\title{
An Automated Security System for Smart Home using Android Application and Arduino
}

\author{
Santhosh Kumar Behera, M.N. Mohanty, Chinmoya Akash Pradhan
}

\begin{abstract}
In modern era home automation plays a vital role because of its high precision and flexibility in using it at different places to save time, energy as well as money by falling down human effort. Key application of the certain technology is about providing a control of the house hold appliances/devices as per selected and directed by the registered user. This work encompasses meticulous information about "Home Automation and security system using GSM module", Arduino \& Android application. The estimate about the number of person available into the room will be improvised whenever the person will enter into the house. According to the double modes i.e. the home automation mode and a security mode the system will act. As in the home automation mode the controlling or appliances/devices will be performed and in security mode the alarm will start ringing. The display will be used to visualize the count about the person exist into that room. In automation approach whenever the chamber will get vacant as the sum total will be zero the light will get "turned OFF" designing the as system power proficient. Furthermore, the person is capable of controlling the home machines/devices by employing his/her cell-phone far away from the home which results in reduction of human effort. For the similar instance of time as the person will arrive into the chamber the alert message will directed to the user's cell-phone using GSM module. The alarm can be controlled via cell-phone Android apps to TURN ON or to TURN OFF it.
\end{abstract}

Keywords: GSM Module, Arduino, Android application, Display (LCD), Home Automation and Security System.

\section{OVERVIEW}

In modern era where automations plays a significant part in the lifespan of human life. It permits to control and monitor the household appliances like light, fan, AC, cooler, $\mathrm{TV}$, fridge, doors etc. It is providing home-based safety and alerting structure to be triggered. Home automations is not only states about dropping human determinations but also save its energy as well as time[1]. The foremost motive of the of the "home automation and security system" is for controlling home applications by employing multiple of practices such as android applications, webpages, GSM whenever any person is very far from its house. The particular system alert's the authorized person in case of an intruder's entry into the chamber by directing alert message to the authorized person's cell-phone that results help the person to guard their own property by monitoring and governing home applications by means of mobile phones as the registered person do not require to go to the location the

Revised Manuscript Received on September 10, 2019.

Santhosh Kumar Behera, Dept. of Computer Sc. Eng., Siksha O

(E-mail: santoshbehera@soa.ac.in)

M.N. Mohanty, Dept. of Electronics \& Communication Eng., Siksha O Anusandhan Deemed to be University, Odisha, India.

Chinmoya Akash Pradhan, Dept. of Electronics \& Communication Eng, Siksha O Anusandhan Deemed to be University, Odisha, India. Anusandhan Deemed to be University, Odisha, India.

(E-mail: mihirmohanty@soa.ac.in)

can operate it at any place where they want by controlling their own appliances and devices[2].

Main motive of "home automation" is "SAVE ELECTRICITY". With the aid of particular expertise everybody can monitor and govern the home appliances or office equipment automatically. The particular system is protected, user-friendly, flexible, reliable \& affordable[1].

Different practices have been deployed in command to implant "home automation and security system" effectively and proficiently. This work paper discourses microcontroller, GSM, and "Android based home automation and security system with their implementation[3]".

Home automation and safekeeping structure based on GSM in addition with android application infers that each and every time a person enters into the chamber with the help of sensors the calculation of amount of persons is be improved automatically, bulb starts to glow \& the buzzer will activated to ring. Total person present in the chamber will be counted and displayed on the desired display screen, and each and every time the room will be bare the person sum total will be nil then the bulb stops illuminating for creating power efficient system[4].

"Home automation and security system based on GSM and android application" entails that each and every time a person will try to come into the chamber then an alert message is directed to the registered user cell-phone which will indicate the presence of intruders into the chamber and the registered user can take some defensive step in command with protecting household from intrusion. More specifically, the user can operate the home applications by deploying the Android apps. By clacking to the specified knob the user is capable of TURN OFF \& TURN ON the applications by means of Android apps[5].

\section{LITERATURE}

\subsection{Arduino Based Home Automation System}

Strategy of home automation system based on Arduino as provided in figure 1. "Arduino is an open source architecture" that uses "Atmega-2 microcontroller". The user interface design of Arduino platform that offers an "integrated development environment (IDE)" Based on the functioning of devices and components used in the particular project. Which needs of $\mathrm{C}$, python, java programming languages and $\mathrm{C}++$. The Arduino is basically of two variations i.e. "Arduino-UNO and Arduino-Mega". Arduino-Uno has twenty pins for input and "Arduino-Mega" has eighty input and output pins. So, more equipment may

Published By:

Blue Eyes Intelligence Engineering

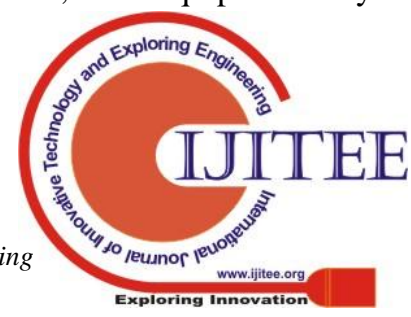


be connected on Arduino-Mega. It's ARM (Advanced RISC Machine) established processor it speed up as processing and functioning[6].

The total figure of people existing in room will be counted by means of the IR sensor. The count will be incremented when both the sensors will count the person present in the room. The display visualizes the total number of count. As the person will enter in the room the clock of second sensor will get developed than the timer of first sensor will indicate it, and as the clock of $1^{\text {st }}$ sensor will be up scaled than the 2 nd sensor will indicate that the person is leaving the room. The bulb will glow as per the presence of the person, if the room will be empty the lights will be switched OFF and when there will be availability of person the light will switch ON. Consequently, the particular system stands power efficient as bulb should run automatically when there is need. The system also provides a security based features as the alarm is attached to the system, as the buzzer starts ringing each and every time the person enters into the room. The buzzer user in the system is piezo buzzer[6].

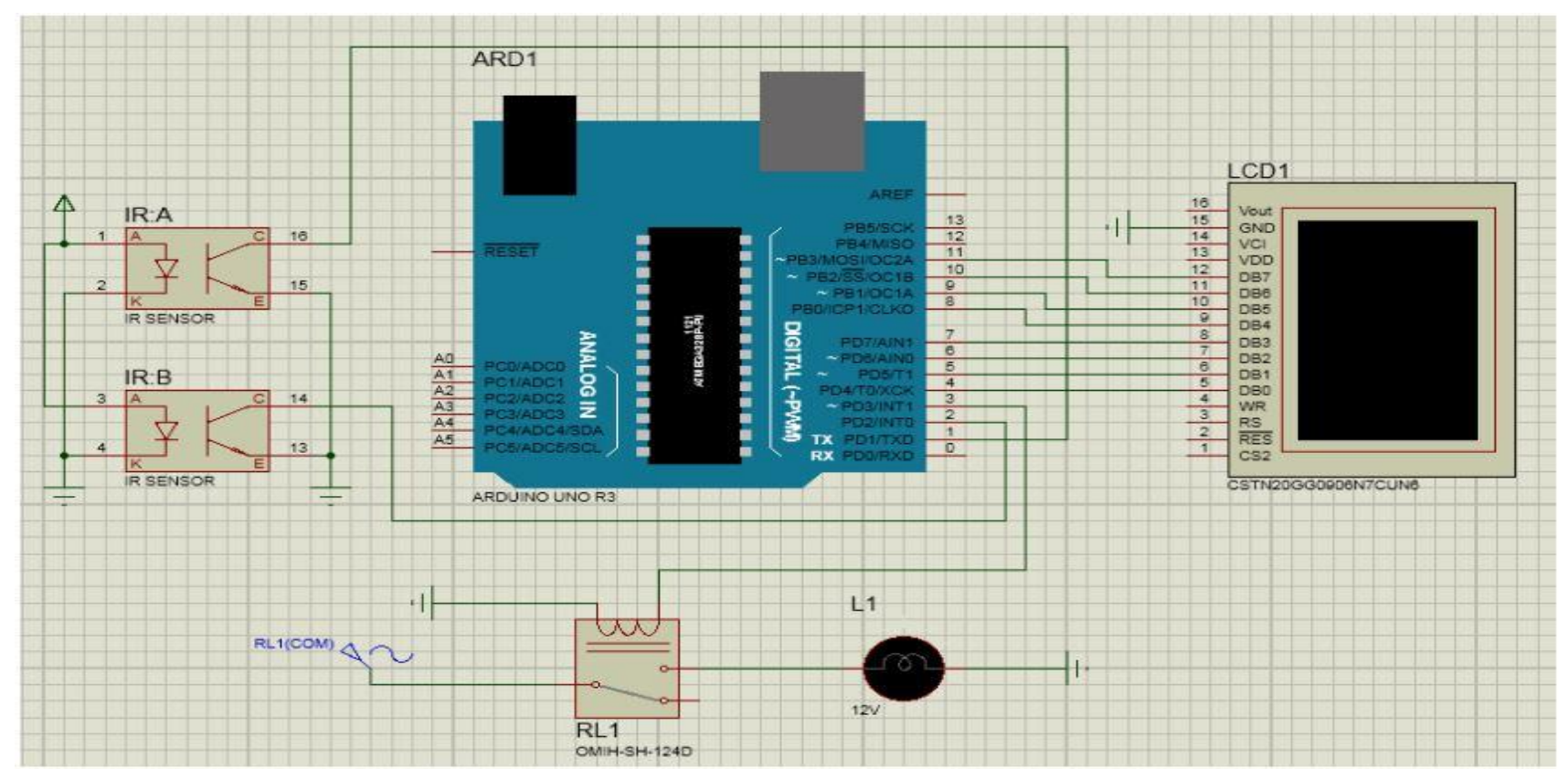

Figure 1. Circuit diagram of home automation based on Arduino.

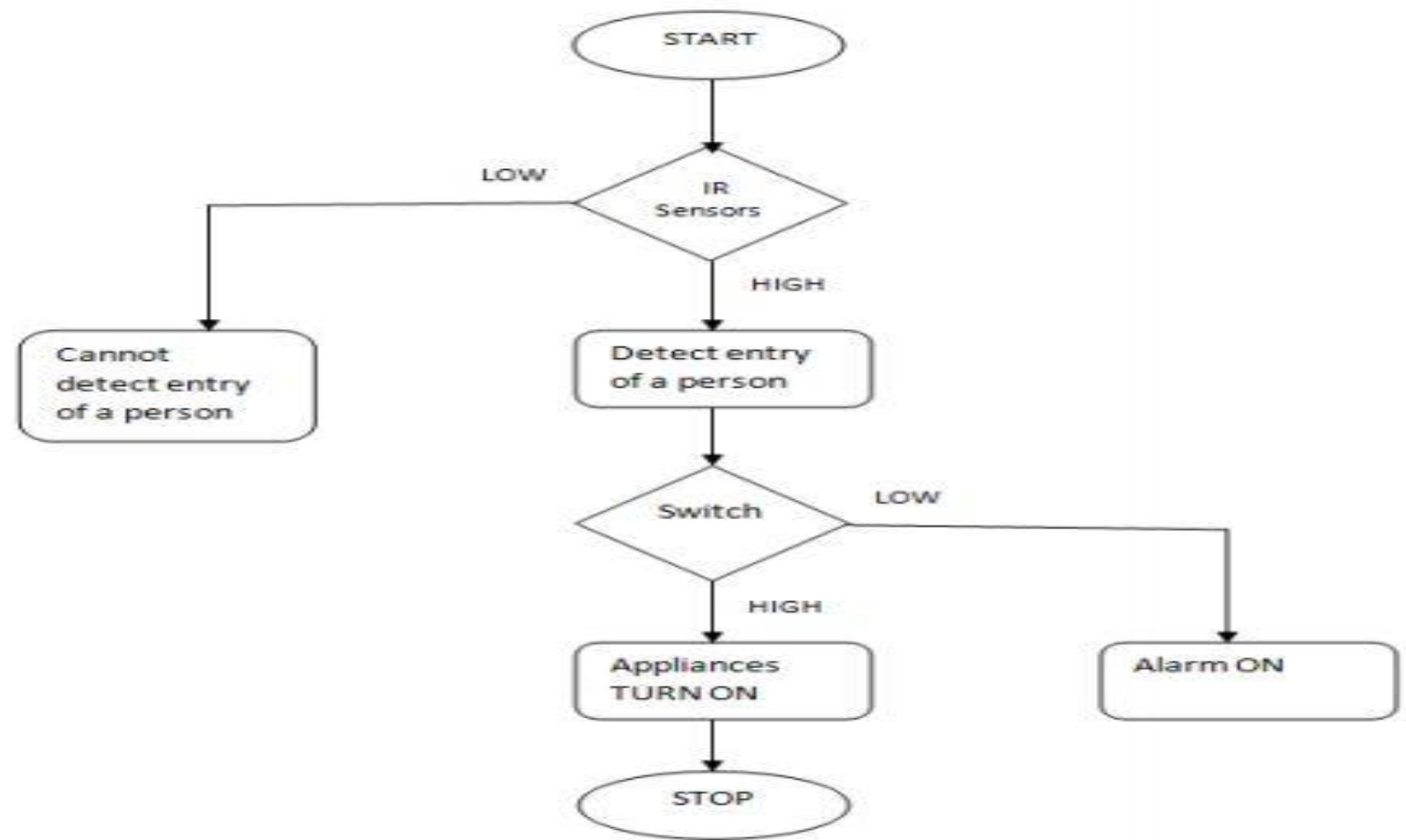

Figure 2. Flow chart of home automation based on Arduino. 


\subsection{Home Automation System Using Android} Applicatoion And Gsm

The online system of home automation system makes it wide spread coverage. Its security features makes it very popular for additional person to trajectory the message/information directed or receive.

To control various appliances/devices via mobile phone we prefer android application. Various appliances/devices can be controlled using android application which is available for the cell-phones and appliances can be controlled far away from the home.

GSM and Android application based security system is illustrated in figure 3.

There is two methods available for system to perform communication-

Global System for Mobile Communication (GSM)

Mobile applications

Messaging is probable by deploying module called as GSM ("ELEMENTZ SIM900A UART"). When security and connectivity is essential for the system the message communication is performed majorly during security mode. The message is sent to the house owner whenever the intruders tries to enter into the house as soon as the user is far away as of the house. Then the user is capable of calling the cops, relatives, neighbours and any friend for the help. More specifically, the alarm will start ringing when an intruder enter into the house when the system is in active mode[7].

In place of shifting the background of the chamber the android app is introduced. It contains various machines/devices that long felt need to be well-ordered employing cell-phone. As soon as the person selects a single app then the act is being achieved on the particular machine/ device via cell-phone. The appliance/device will be either switched ON or it will be switched OFF as directed by the user. The buzzer can be performed using same android app available on the cell-phone[7].

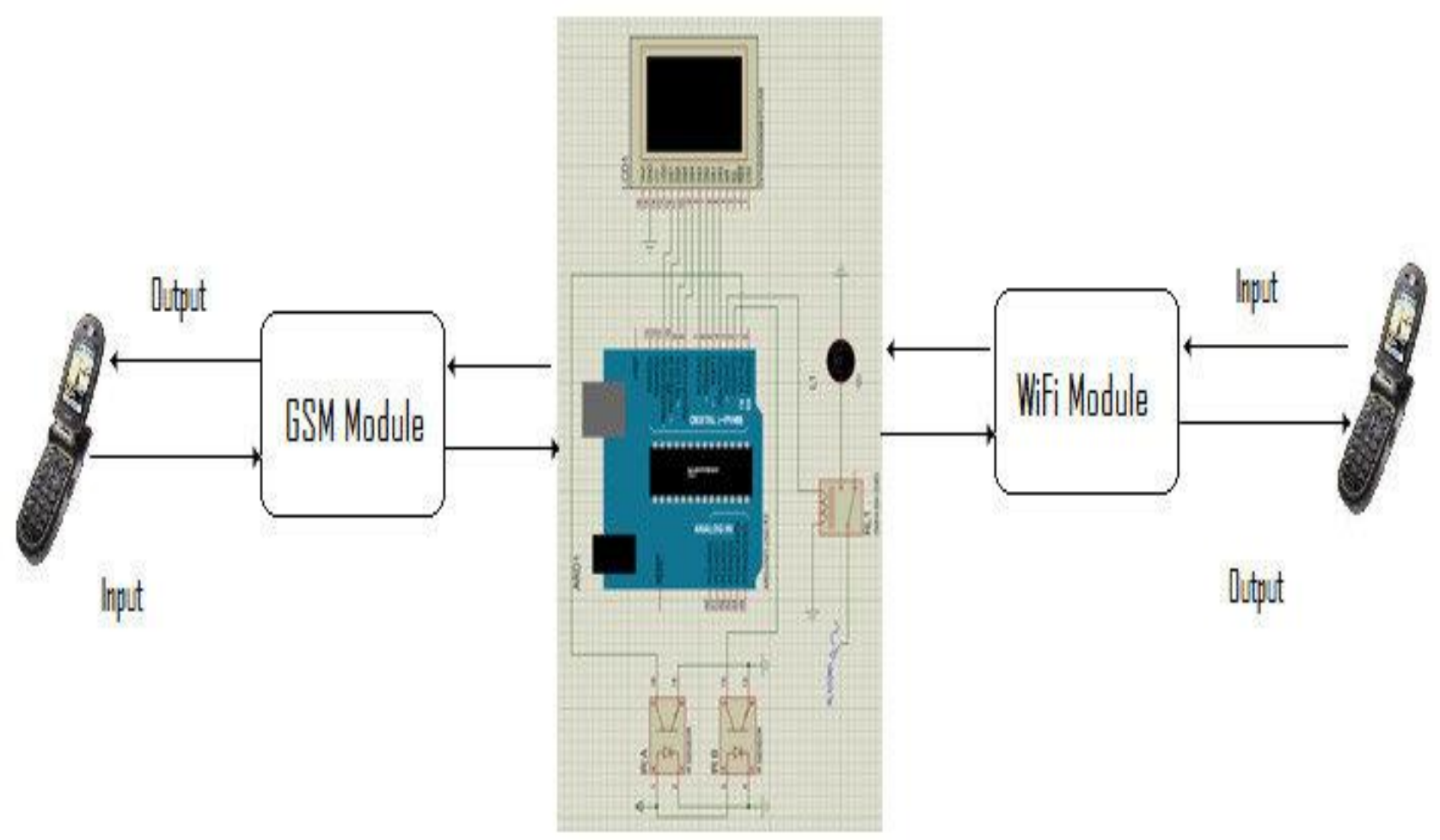

Figure 3. Connection diagram of home automation based on GSM module and android application.

There are two types possible for communication-

- Input

- Output

Registered user directs new outline to the system employing message and android application in input communiqué. In the protected mode the input communication is required. The message is sent to the registered user whenever the person enters or tries to enter into the house. 


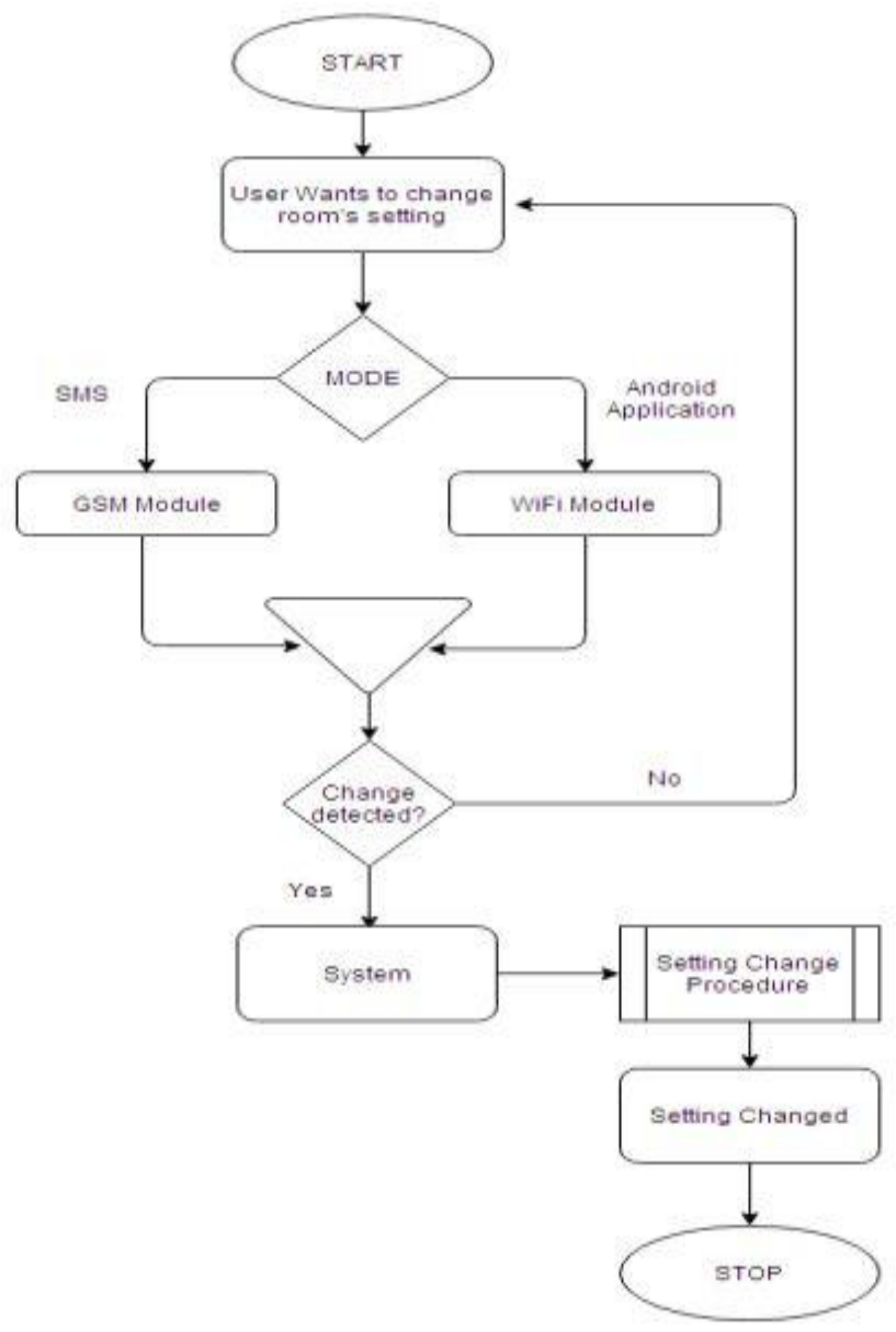

Figure 4. Input communication flow chart

The two modes is available for output communication-

- $\quad$ Message (SMS via GSM module)

- $\quad$ Android apps

GSM module is used for sending an alert message to the user cell-phone in output communication system. The message is being sent by employing GSM on registered

user's cell-phone indicates the availability of intruders into the chamber. Also to change settings of the house and appliances/devices in the house the output communication is required and it will also monitor the system continuously using android applications. They can be controlled using application present on the cell-phones[3]. 


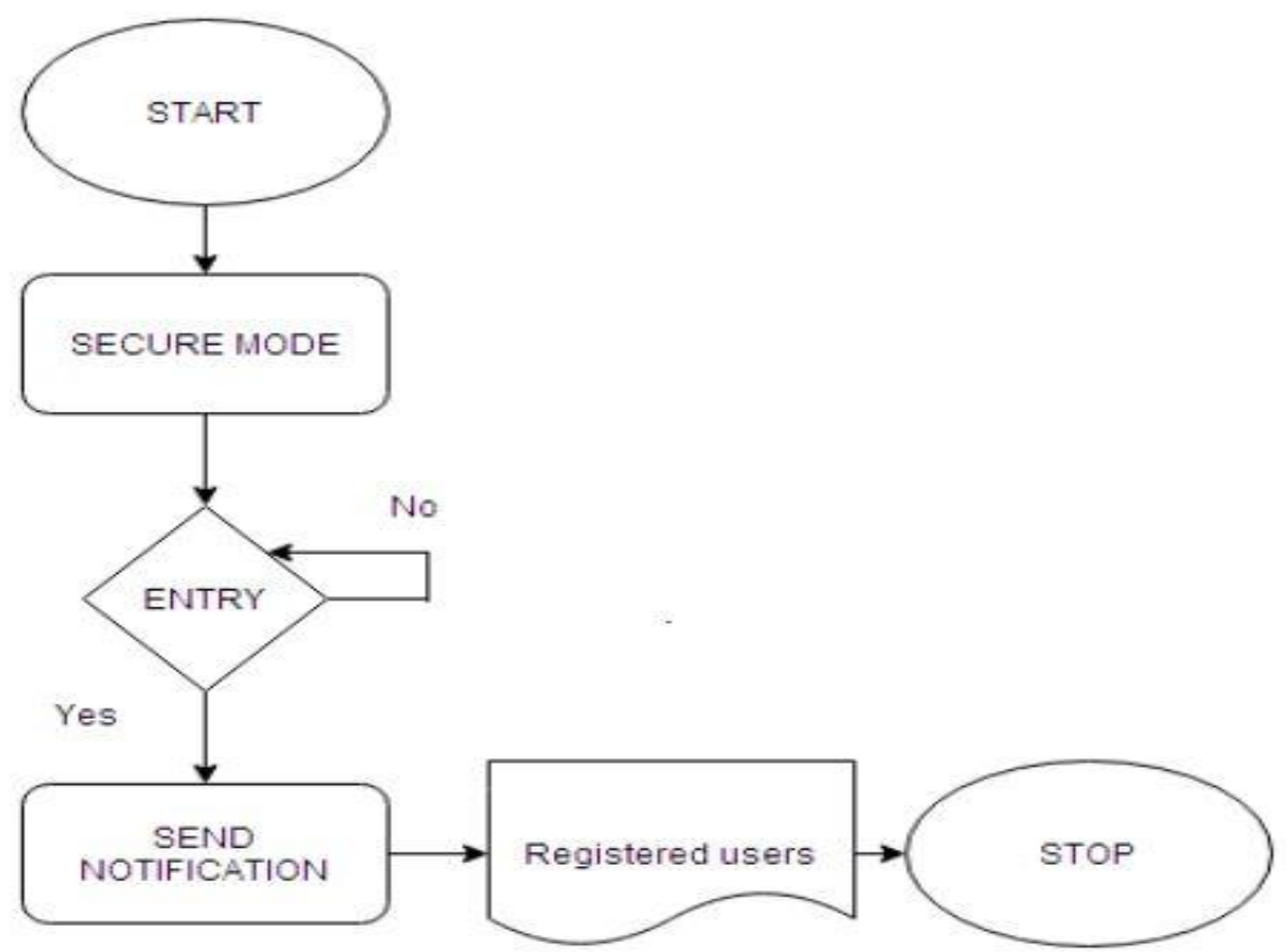

Figure 5. Output communication flow chart

\section{METHODOLOGY \& RESULTS}

The proposed system works in two parts as follows

- Home automation: Appliances/devices controlling and monitoring, and

- Security system: alert regarding intrusion detection.

In first part the user first decide the objects to be controlled according to his/her ease. Then the objects are controlled via microcontroller i.e. Arduino which takes the input of individual presence and according to that it controls the appliances and devices accordingly. When there is zero count of the person in the room then the light will be turned off to save energy and when there is availability of the person then the light will be turned on this operation can be applied for the any appliance of the house according to the requirement of the user.

In second part the user will be alerted/informed about the person count as well as the intrusion. The display associated with system that shows real period count of available person in the room and also the increment and decrement of the person in the room. The user will be also alerted via cellphone about the intrusion detection.

Both the parts of the system can be monitored and controlled by the cell-phone using Android application. The user can switch ON/OFF the appliances and devices using cell-phone far away from the house and also the alert message is directed on the user's registered cell-phone in case any intrusion detection.

\section{CONCLUSIONS}

Commencing the work paper, we determined the wireless technology is being used by all the "home automation system technology". Arduino, "Android and GSM based home automation system" has been implanted that provides the people comfort to control \& monitor the appliance/devices. Different "home automation system using Arduino", GSM \& Android techniques are provided with its strategy \& also implemented its flow-charts that provides the outline of its weaknesses and strengths.

Home automation system is mainly used to provide the security and control different devices/appliances using their cell-phones \& also to "save electricity", money \& energy. Particular system is likewise been used to guard the human as of the intrusion with the alarm system provided by the system. It will start to ring whenever the intrusion will be detected to inform the registered user of house for its safety purpose. This particular system will also visualize the count of the person present in the room and also the live count will be there to ensure the real time count.

\section{REFRENCES}

1 Y. Strengers and Y. Strengers, "Home Automation," in Smart Energy Technologies in Everyday Life, 2016.

2 V. S. Gunge and P. S. Yalagi, "Smart Home Automation: A Literature Review," Int. J. Comput. Appl., 2016.

3 D. Sona, A. Choudhary, and A. K. Goyal, "Home automation using GSM," Int. J. Appl. Eng. Res., 2015.

4 R. Parasuraman and V. Riley, "Humans and Automation: Use, Misuse, Disuse, Abuse," Hum. Factors J. Hum. Factors Ergon. Soc., 1997.

5 C. Gomez and J. Paradells, "Wireless home automation networks: A survey of architectures and technologies," IEEE Commun. Mag., 2010.

Published By: 
6 N. David, A. Chima, A. Ugochukwu, and E. Obinna, "Design of a Home Automation System Using Arduino," Int. J. Sci. Eng. Res., 2015.

7 M. A. E.-L. Mowad, A. Fathy, and A. Hafez, "Smart Home Automated Control System Using Android Application and Microcontroller," Int. J. Sci. Eng. Res., 2014. 